\title{
Integrated Acoustic and Thermo-Fluid Insulation Modeling of an Airflow Window with a Photovoltaic Solar Wall
}

\author{
Himanshu Dehra \\ Egis India Consulting Engineers Pvt. Ltd \\ Gurugram (Haryana), India \\ Email: anshu_dehra@hotmail.com
}

\begin{abstract}
A simulation model is proposed for integrated acoustic and thermo-fluid insulation constituting an airflow window with a photovoltaic (PV) solar wall spandrel section. The physical model of an outdoor test-room comprises of a wooden framed double or cavity wall assembly with: (i) a triple glazed fenestration section with a closed roller blind; (ii) a solar wall spandrel section of double-glass PV modules and back panel of polystyrene filled plywood board; and (iii) fan pressure based manually operated inlet and exhaust dampers with ventilation through exhaust fan for transportation of heat. A generalized two-dimensional analysis of a double wall structure is illustrated by placement of surface and air nodes into two adjacent stacks of control volumes representing outer and inner walls. Integrated noise insulation and energy conversion model is presented. The energy conversion and noise insulation model is supported with some numerical results using devised noise measurement equations.
\end{abstract}

\section{Introduction}

The passage of air in and out-and heat along with it- is called infiltration. The significance of infiltration is clear from the fact that the average house has $600 \mathrm{~cm}^{2}$ of vents and flues alone; plus window frames, doors, sills, and corners that need sealing and plugging; fireplaces with unfit dampers; and a front door that is slammed 3000 times a year. Air passes in and out through these openings. Therefore, infiltration is a misleading word since it only denotes a one way movement of air into a house. There is need of better word than breathing or respiration or exchange. Focusing entirely on insulation thickness, the best way to define all flow of air in and out through unsealed slits and unplugged holes is by huff and puff of a house. Due to slit between the sash and the frame or the frame and the house, a $1.25 \times 1.25-\mathrm{m}$ double glazed window will easily lose about 70 liters of oil in winter, and some studies have suggested that windows account for even more heat loss than roofs. Double or triple panes are not the only solution. Traditionally, the most effective defense is solid, thermal shutters, put up from the inside that fit the window hole exactly.

This paper attempts to bring up integrated noise insulation modeling for airflow windows along with their use as a sustainable energy source of electric and thermal energy besides providing daylighting. The airflow window system with photovoltaic modules embedded in solar wall spandrel as illustrated in Figure 1 has been considered for investigations (Dehra, 2002; Dehra, 2011). A triple glazed airflow window combined with a PV solar wall spandrel has many advantages: (i) airflow window provides electric power, hybrid ventilation through heating/cooling, daylighting and reduction in green house gas emissions by energy conservation of fossil fuels; (ii) it provides integrated sound and thermal insulation; (iii) it gives protection from excessive heating from solar radiation by passing and controlling the amount of heat transport; (iv) it gives protection to PV modules from excessive heating, weather deterioration including protection from snow and dust; (v) with frame supporting structures, the system is easily approachable for repair and maintenance jobs; and (vi) it has better aesthetic appearance to the occupants and to the viewers from outside in comparison with stand alone PV module power generating system.

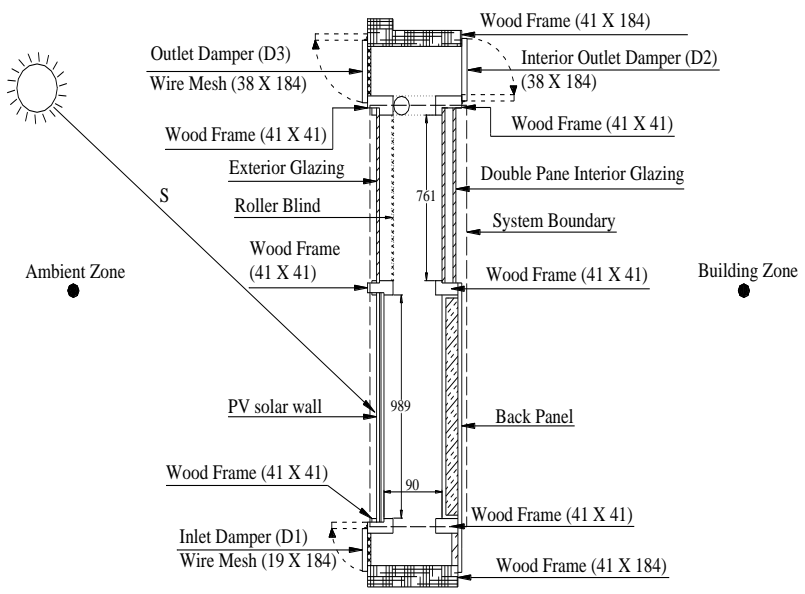

Figure 1: Schematic of an airflow window system with a $P V$ solar wall spandrel section (Dimensions provided are in $\mathrm{mm}$ ).

\section{Physical Model Description}

A full scale experimental test section comprising an airflow window with a single pane exterior glazing and a double pane interior glazing and a photovoltaic solar wall spandrel was constructed in an outdoor room facility at Concordia University, Montréal, Québec (Dehra, 2004). The transportation of heat was achieved through manually operated intake and set of exhaust dampers. The intake and exhaust dampers located on 
exterior side were fitted with wire mesh screens. The exhaust damper placed on the interior side towards outdoor room is for allowing the pre-conditioned outdoor air directly into the room indoor environment. The air movement in the airflow window system was achieved through: (i) buoyancy-induced hybrid flow; and (ii) fan-assisted flow created either in absence or presence of wind-induced flow.

In airflow window integrated with PV module, there are many issues related to its operation. The main objective is to model the integrated thermal and sound insulation fields and to maximise the value of total energy generated and therefore increase the combined efficiency of the system. In achieving this objective the heat transfer model and losses of PV model need to be studied. The heat can be recovered from the heated PV modules in different ways. One of the options is to treat the heated PV module as absorber surface and pass airflow through the surface. The key operation parameters are air mass flow rate, area of the absorber surface (PV, Blind) and its temperature. Air mass flow rate requires optimum air velocity under various conditions to prevent condensation, stagnant zones, flow reversal and other adverse effects that will cause deterioration of the PV panels. This optimisation of airflow will maximize the absorbed solar radiation conversion to either thermal or electric power. By placing motorised blind after the integrated PV, will achieve twin objectives, control the amount of daylight transmission and also help in absorbing the excess external heat, which is going inside the room and overheating it. This heat is further taken from blind by mass flow of air, while cooling the PV modules. Depending on the climatic variables the operation of airflow window can be optimised. Damper motion is controlled by both flow and temperature sensors. During the summer, in the daytime, when outside air temperature is in the range of $15^{\circ} \mathrm{C}-22^{\circ} \mathrm{C}$, the exhaust air vent provided will exhaust the heated air from PV modules to outside. But during night, the cooled fresh air can be used inside the room to reduce the cooling load of the building. Another important aspect is to control the amount of daylight transmission by optimising sizing and distribution of opaque photovoltaic modules for maximising the value of thermal and electric power generated.

\section{State-of-the-Art}

Traditionally, insulation is dead air space, or a dead gas space, sometimes combined with a reflective surface. Air has a low inherent conductivity. If it is dead or motionless there is no convection and when there is a reflective surface, radiation is cut to a minimum. Dead air space can be found in materials like fiberglass blanket, loose-fill and foam. They embody thousands of tiny pockets where dead air is encased, protected and preserved.

Outdoor duct system consists of combination of fans, duct construction elements, heat exchangers and air filters. The location of fan in outdoor duct is decided by the direction of flow and desired pressure relations. A supply fan is used to pump air into a space and exhaust fan is used to draw air out of a space. The pressure relations for the two cases are different. There is a buildup pressure in case of supply air and reduction of pressure in case of exhaust air. The space pressure is determined based on the relative quantity of air handled by supply and exhaust air. The space pressure will be positive if there is an excess supply air in comparison to exhaust air and negative if there is an excess exhaust air in comparison to supply air.

The total energy provided by the fans to the air passing through a given system is fixed, assuming the same capacities and end pressures for a supply fan, an exhaust fan or both are used. A motor-driven fan is used to circulate filtered heated air from outdoor duct through supply duct to outdoor test-room. As the hot air is delivered through the ducts and into the room through the supply outlet, cooler air from the room is being returned through return grilles, into the exhaust air duct.

The choice of fan is dependent on creating a sufficient pressure is achieved to overcome the total losses based on the flow through the duct with longest run. Fan performance must meet and match system requirements. The only possible operating characteristic points are those where the system curve intersects the fan curve. These are the points where the pressure developed by the fan exactly matches the system resistance, and the flow in the duct system equals the fan capacity. The overall system resistance is calculated by summing the pressure losses for the individual components along any one flow path.

Air passing through the outdoor duct system is either heated or cooled. It results in decreased or increased density respectively and with assumption of constant mass flow rate, its total volume rate will be increased or decreased accordingly. The developed resistance in the duct is calculated based on actual gas density, volume, and velocity through it. The total system resistance is calculated by summation of these resistances along the flow path.

The difference in power requirements at various locations can be calculated. For the case of constant system resistance, the pressure required for the fan (P2$\mathrm{P} 1)$ will be constant regardless of the location. The volume of air flow (Q) will vary with the location. The fan location with least power requirements is that place where density of air will be highest assuming constant efficiency.

Exterior duct insulation can be attached with adhesive, with supplemental pre-attached pins and clips, with wiring or bands. Liners can be attached with adhesive and supplemental pins/clips. Rectangular ducts and fittings are fabricated by grooving, folding, and taping with metal accessories such as turning vanes, splitters, and dampers incorporated into the system. If rectangular ducts exceed the pre-determined dimensions for particular static pressure, the ductwork must be reinforced. Insulation can significantly reduce operating 
costs that depend upon unit cost of heating and cooling energy, extent of duct exposed to outside conditions. In addition, duct insulation maintains the supply air temperature unaltered thereby, maintaining the conditioned space within acceptable temperature range. Vapor retarders are required on exterior insulation of ducts that are used for alternate heating and cooling.

Some thermal insulation materials can also serve purpose of sound control (Asdrubali et al, 2015). Acoustic efficiency depends upon physical structure of the material. Materials with open, porous surfaces have sound absorption capability (Asdrubali et al, 2012). Those with high density and resilient character can be used for absorption of vibrations. Insulation for sound conditioning includes flexible and semi-rigid, formed-inplace fibrous materials and rigid fibrous insulation. Thermal insulation materials improve their sound insulation when installed with discontinuous construction. A wall of staggered stud construction that uses resilient clips or channels on one side of the stud or resilient boards of special manufacture to prevent acoustic coupling mechanically between the surfaces, reduces sound transmission. Sound absorption by thermal insulation blanket in a cavity wall reduces sound transmission.

The energy conversion and noise characterization in an exterior double wall is important, for example, in modeling PV solar wall and transpired unglazed structures (Dehra, 2018a; Dehra 2018b, Dehra 2018c, Dehra 2018d, Dehra 2019). The energy conversion in a double of cavity wall is a function of solar irradiation, air gap width, mass flow rate and pressure, wall and air temperatures. A generalized two dimensional thermal analysis of an outdoor duct is presented by placement of surface and air nodes into two adjacent stacks of control volumes representing outer and inner walls of duct. A matrix solution procedure is adopted by constituting conjugate heat exchange of conduction, convection, radiation and ventilation heat transport.

The requisite amount of ventilation air in a building in a given climate depends on heating/cooling load. The HVAC load on building varies with the condition of outdoor ventilation air that may require additional heating, cooling and humidification or dehumidification. In temperate climates, outdoor air is more economical to use than recycled return air. The analysis of double or cavity wall for ventilation purposes using airflow window with PV solar wall structures is investigated. The investigation of energy conversion, ventilation and integrated insulation system is based on complete information for the given design conditions and limitations of operation results.

\section{Model Assumptions and Development}

The assumptions used in the development of the model for a Building Integrated Photovoltaic Airflow Window (BIPV-AW) system as depicted in Figure 1 are: (i) fully developed heat transfer has been assumed for mixed convection heat transfer assuming a parallel plate wide channel at low air velocities $\sim 0.5 \mathrm{~m} / \mathrm{s}$; (ii) temperature variation only along $\mathrm{y}$-axis with lumped temperature distribution along $\mathrm{x}$ and z-axes; (iii) applicability of first law of thermodynamics at the surface; (iv) clear sky is applicable; (v) quasi steady state heat transfer analysis has been performed assuming a vertical channel; (vi) uniform average air velocity distribution; (vii) temperature variation only in y-direction (vertical), being taken as lumped in other directions (x-axis and $\mathrm{z}$-axis); (viii) air properties are evaluated at film temperature of $300 \mathrm{~K}$; (ix) negligible heat transfer from side walls/insulation panel and room air zone; $(\mathrm{x})$ conduction (diffusion) equation for performing energy balance on air nodes is not taken into consideration; (xi) negligible thermal storage capacity of duct wall; (xii) no infiltration or air leakage sources from the test section; and (xiii) ambient air and room air temperatures are specified.

The system is discretised into network of two adjacent stacks of control volumes common to surface and air nodes (see Figure 2). The energy balances are performed on both surface and air nodes with aid of constitutive relations for noise fields due to solar intensity, sound intensity, airflow power intensity, electric power intensity and heat power intensity. The energy conversion and noise characterization is important, for example, in modeling airflow window and PV solar wall building structures. The resultant noise field due to composite wave elements (of heat, fluid, electricity, sound and sun) is a function of solar irradiation, sound intensity, air gap width, mass flow rate and pressure, wall and air temperatures of the double wall building structure. The integrated noise insulation due to thermal and sound fields is modeled. Noise characterization equations are devised, which calculate noise fields due to ventilation, heat transport and sound transmission of integrated building insulation through a double wall structure.

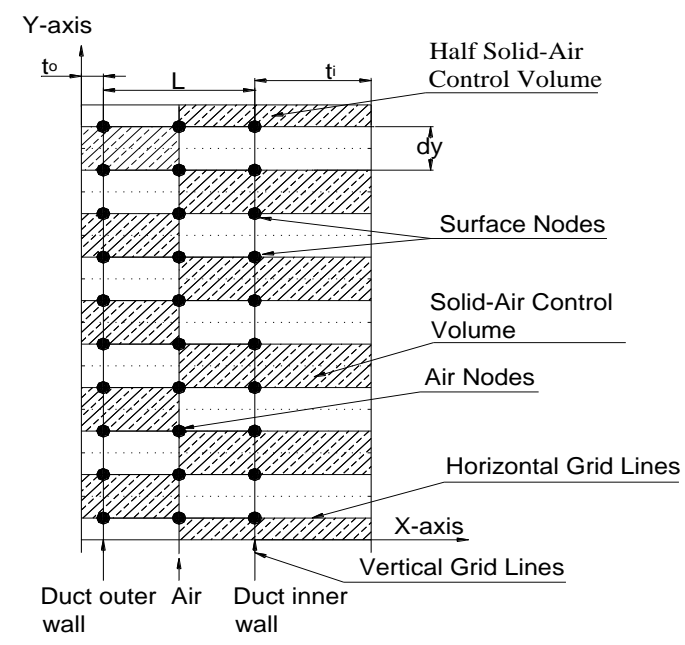

Figure 2: Grid size in the duct: distribution of nodes and control volumes.

In writing nodal equations in matrix form, sign notation is adopted for automatic formulation of conductance matrix (U-matrix) with unknown temperatures and heat source elements. The sum of all incoming heat source elements and U-matrix conductances multiplied with 
temperature difference with respect to the unknown temperatures at other nodes are equal to zero. The energy balance is written in equation form for any general node $(\mathrm{m}, \mathrm{n})$ :

$$
\sum_{\mathrm{n}=1}^{\mathrm{N}}\left(\mathrm{U}_{\mathrm{m}, \mathrm{n}} \times \Delta \mathrm{T}_{\mathrm{m}, \mathrm{n}}\right)+\sum_{\mathrm{n}=1}^{\mathrm{N}} \mathrm{Q}_{\mathrm{m}, \mathrm{n}}=0
$$

Where $U_{m, n}$ is the conductance at node $(m, n), \Delta T_{m, n}$ is the difference between unknown temperature at the node $(\mathrm{m}, \mathrm{n})$ and unknown temperature at surrounding heat exchange node. $\mathrm{Q}_{\mathrm{N}}$ is heat source term at the node $(\mathrm{m}, \mathrm{n})$.

\section{Noise Characterization}

A unified theory for stresses and oscillations is proposed by the author (Dehra 2007). The following standard measurement equations are derived and adopted from the standard definitions for sources of noise interference (Dehra 2008 b; Dehra 2016; Dehra 2017; Dehra 2018 c).

Noise of Sol: For a pack of solar energy wave, the multiplication of solar power storage and the velocity of light gives solar power intensity I. On taking logarithm of two intensities of solar power, $I_{1}$ and $I_{2}$, provides intensity difference. It is mathematically expressed as:

Sol $=\log \left(I_{1}\right)\left(I_{2}\right)^{-1}$

Whereas logarithmic unit ratio for noise of sol is expressed as Sol. The oncisol (oS) is more convenient for solar power systems. The mathematical expression by the following equality gives an oncisol $(\mathrm{oS})$, which is $1 / 11^{\text {th }}$ unit of a Sol:

$o S= \pm 11 \log \left(I_{1}\right)\left(I_{2}\right)^{-1}$

Noise of Therm: For a pack of heat energy wave, the multiplication of total power storage and the velocity of light gives heat power intensity I. The pack of solar energy wave and heat energy wave (for same intensity I), have same energy areas, therefore their units of noise are same as Sol.

Noise of Photons: For a pack of light energy beam, the multiplication of total power storage and the velocity of light gives light power intensity I. The pack of solar energy wave and light energy beam (for same intensity I), have same energy areas, therefore their units of noise are same as Sol.

Noise of Electrons: For a pack of electricity wave, the multiplication of total electrical storage and the velocity of light gives electrical power intensity I. The pack of solar energy wave and electricity wave (for same intensity I), have same energy areas, therefore their units of noise are same as Sol.

Noise of Scattering: For a pack of fluid energy wave, the multiplication of total power storage and the velocity of fluid gives fluid power intensity I. On taking logarithm of two intensities of fluid power, $I_{1}$ and $I_{2}$, provides intensity difference. It is mathematically expressed as:

Sip $=\log \left(I_{1}\right)\left(I_{2}\right)^{-1}$

Whereas, logarithmic unit ratio for noise of scattering is
Sip. The oncisip (oS) is more convenient for fluid power systems.

The mathematical expression by the following equality gives an oncisip (oS), which is $1 / 11^{\text {th }}$ unit of a Sip:

$o S= \pm 11 \log \left(I_{1}\right)\left(I_{2}\right)^{-1}$

For energy area determination for a fluid wave, the water with a specific gravity of 1.0 , is the standard fluid considered with power of $\pm 1 \mathrm{Wm}^{-2}$ for a reference intensity $\mathrm{I}_{2}$.

Noise of Scattering and Lightning: For a pack of fire wave, the intensity, I, of fire flash with power of light, is the multiplication of total power storage and the velocity of light. Whereas for a pack of fire wave, the intensity, I, of fire flash with power of fluid, is the multiplication of total power storage capacity and velocity of fluid.

- For a noise due to fire flash, the collective effect of scattering and lightning is obtained by superimposition principle.

- For same intensity I, the pack of solar energy wave and a fire flash with light power have same energy areas, therefore their units of noise are same as Sol. The therm power may also be included in fire flash with power of light.

- For same intensity I, the pack of fluid energy wave and a fire flash with fluid power have same energy areas, therefore their units of noise are same as Sip. In determining the areas of energy for the case of fluids other than water, a multiplication factor in specific gravity has to be evaluated.

Noise of Elasticity: For a pack of sound energy wave, the product of total power storage and the velocity of sound gives sound power intensity I. On taking logarithm of two intensities of sound power, $I_{1}$ and $I_{2}$, provides intensity difference. It is mathematically expressed as:

$\mathrm{Bel}=\log \left(I_{1}\right)\left(I_{2}\right)^{-1}$

Whereas, logarithmic unit ratio for noise of elasticity is Bel. The oncibel (oB) is more convenient for sound power systems. The mathematical expression by the following equality gives an oncibel $(\mathrm{oB})$, which is $1 / 11^{\text {th }}$ unit of a Bel:

$$
o B= \pm 11 \log \left(I_{1}\right)\left(I_{2}\right)^{-1}
$$

There are following elaborative points on choosing an onci as $1 / 11^{\text {th }}$ unit of noise (Dehra $2018 \mathrm{c}$ ):

i) Reference value used for $\mathrm{I}_{2}$ is $-1 \mathrm{~W} \mathrm{~m}^{-2}$ on positive scale of noise and $1 \mathrm{~W} \mathrm{~m}^{-2}$ on negative scale of noise. In a power cycle, all types of wave form one positive power cycle and one negative power cycle (Dehra 2008 a). Positive scale of noise has 10 positive units and one negative unit. Whereas, negative scale of noise has 1 positive unit and 10 negative units;

ii) Each unit of sol, sip and bel is divided into 11 parts, 1 part is $1 / 11^{\text {th }}$ unit of noise;

iii) The base of logarithm used in noise measurement equations is 11 ; 
iv) Reference value of $I_{2}$ is $-1 \mathrm{~W} \mathrm{~m}^{-2}$ with $I_{1}$ on positive scale of noise, should be taken with negative noise measurement expression (see Eqs 3, 5 and 7), therefore it gives positive values of noise;

v) Reference value of $I_{2}$ is $1 \mathrm{~W} \mathrm{~m}{ }^{-2}$ with $I_{1}$ on negative scale of noise, should be taken with positive noise measurement expression (see Eqs 3, 5 and 7), therefore it gives negative values of noise.

The choosing of onci in noise units is done so as to have separate market product \& system of noise scales and their units distinguished from prevailing decibel units (which has its limitations) in the International System of Units. More discussions on energy conversion, noise characterization theory and choice of noise scales and its units are presented in many papers by the author (Dehra 2008a, Dehra 2008b, 2018c, Dehra 2018d, Dehra 2019).

\section{Results and Discussions}

The picture of the experimental setup in a prefabricated outdoor room is presented in Figure 3. The solar noon annual solstices and equinoxes days are selected for performing sensitivity analysis to achieve range of: (i) temperatures of pre-conditioned fresh air available; (ii) electric power generation vis-à-vis surface temperatures of photovoltaic modules; (iii) integrated noise insulation values due to noise fields of composite wave elements transmitted into the room. Computer aided simulation model is developed for an airflow window system located in Montréal. Some examples of noise insulation calculations are illustrated using newly devised noise measurement equations for noise of sol, noise of therm, noise of scattering and noise of elasticity. The sensitivity analysis for an outdoor duct is also conducted for critical design of ventilation requirements with supply of varying outdoor mass flow rate to a single building zone. The improved method is useful for accurately predicting ventilation air requirements along with designing integrated thermal and sound insulation through a double or cavity wall building structure.

Table 1 has provided properties of physical domain. Tables 2, 3, 4 and 5 have presented sensitivity analysis and noise characterization values for the exterior duct based on mass flow rate, solar irradiation and size of duct. The thermal modeling results are presented from Figures 4 to 8 . Figure 4 has presented efficiencies of the building integrated photovoltaic airflow window system viz., electrical efficiency of PV Module and combined efficiency of the system. Figure 5 has presented thermal model results of PV Module, insulation panel and air with respect to height of the spandrel section. Figure 6 has presented thermal model results for PV Module temperatures with solar time for forced and natural convection and air temperatures for forced and natural convection for air cavities I and II. Figure 7 has results for useful energy generated and solar energy absorbed by a photovoltaic module. Figure 8 has provided variation of hydraulic diameter, velocity and flow rate vs pressure drop on a log scale.
The thermo-physical properties of photovoltaic modules, air and insulating panel were assumed constant along all directions i.e. $\mathrm{x}, \mathrm{y}$, and $\mathrm{z}$-ordinates. The thermo-physical properties of insulating panel with building insulation were obtained from tests conducted with heat flow meter and related specifications from the manufacturer (Dehra, 2004). The temperature differences along $\mathrm{x}$-direction are obtained by assuming same temperature difference per unit thickness of material along $\mathrm{x}$ and $\mathrm{y}$-ordinates (Dehra, 2004). The heat storage capacity for temperature differences across $\mathrm{x}$-direction is negligible of the heat storage capacity for temperature differences across $y-$ direction. Therefore temperatures are assumed uniform and lumped in $\mathrm{x}$-direction. The pair of glass coated photovoltaic modules was having three layers of material viz., a flat sheet of solar cells, with glass face sheets on its exterior and interior sides. The measurements were collected for a pair of successive runs at same solar intensities (Dehra, 2004). The thermal model is validated by comparing its predicted results with those obtained from the experimental apparatus. The agreement between the predictions of the thermal model and experimental results was presented to be very good (Dehra, 2004).

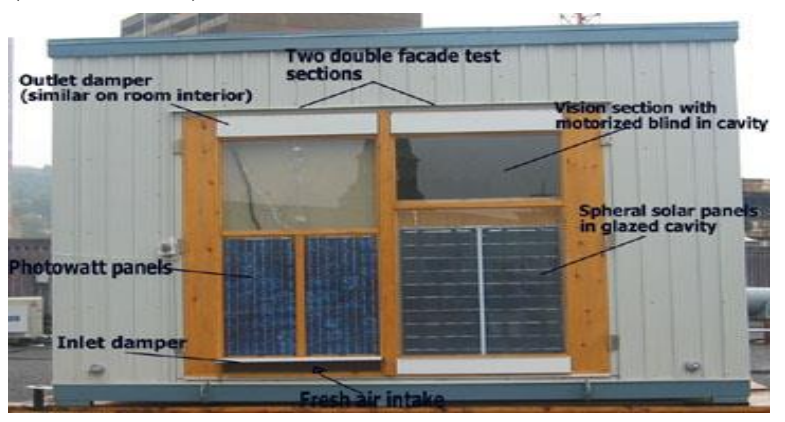

Figure 3: Prefabricated outdoor room at Concordia University.

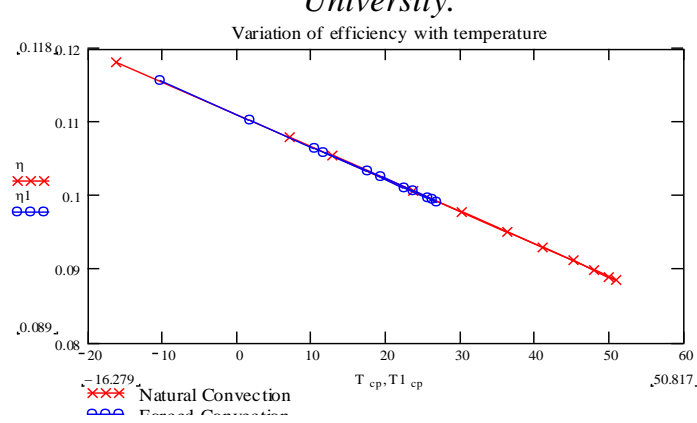

(a)

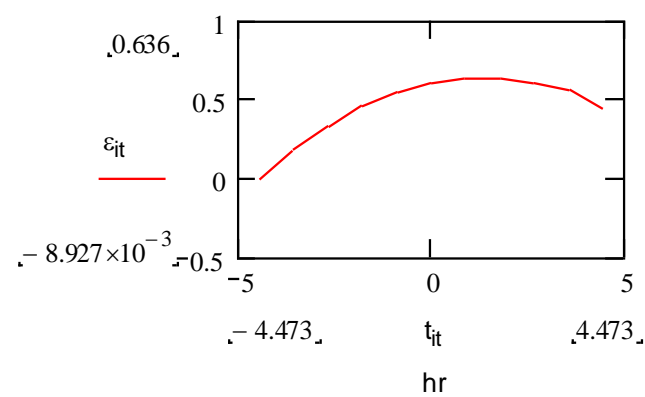

(b)

Figure 4: Efficiencies: (a) Electrical Efficiency of PV Module; (b) Combined efficiency of the system. 
Table 1: Properties of Physical Domain.

\begin{tabular}{|c|c|c|c|}
\hline Property & Value & Property & Value \\
\hline Solar irradiation & $650 \mathrm{~W} \mathrm{~m}^{-2}$ & Width of air gap & $0.025 \mathrm{~m}$ \\
\hline Ambient heat transfer coefficient & $13.5 \mathrm{~W} \mathrm{~m}^{-2} \mathrm{~K}^{-1}$ & Thermal conductivity of air & $0.02624 \mathrm{~W} \mathrm{~m}^{-1} \mathrm{~K}^{-1}$ \\
\hline Ambient air temperature & $-5^{\circ} \mathrm{C}$ & Specific heat of air (cp) & $1000 \mathrm{~J} \mathrm{~kg}^{-1} \mathrm{~K}^{-1}$ \\
\hline Building space temperature & $20^{\circ} \mathrm{C}$ & Density of air & $1.1174 \mathrm{~kg} \mathrm{~m}^{-3}$ \\
\hline Height of duct & $3.0 \mathrm{~m}$ & Kinematic viscosity of air & $15.69 \times 10^{-6} \mathrm{~m}^{2} \mathrm{~s}^{-1}$ \\
\hline Width of duct & $1.0 \mathrm{~m}$ & Prandtl number of air & 0.708 \\
\hline Thickness of outer wall of duct & $0.0025 \mathrm{~m}$ & $\begin{array}{l}\text { Air velocity for obtaining mass } \\
\text { flow rate }\end{array}$ & $0.75 \mathrm{~m} \mathrm{~s}^{-1}$ \\
\hline Absorbtance of outer wall with flat black paint & 0.95 & $\begin{array}{l}\text { Stefan Boltzmann constant for } \\
\text { surface of duct walls }\end{array}$ & $5.67 \mathrm{X}_{10-8} \mathrm{~W} \mathrm{~m}^{-2} \mathrm{~K}^{-4}$ \\
\hline $\begin{array}{l}\text { Thermal conductivity of Aluminium alloy for HVAC } \\
\text { duct }\end{array}$ & $137 \mathrm{~W} \mathrm{~m}^{-1} \mathrm{~K}^{-1}$ & $\begin{array}{l}\text { Emissivity of back surface of duct } \\
\text { walls }\end{array}$ & 0.95 \\
\hline RSI value & $1.0 \mathrm{~m}^{2} \mathrm{~K} \mathrm{~W}^{-1}$ & Number of nodes in $\mathrm{x}$ - direction & $\mathrm{Nx}=3$ \\
\hline Thickness & $0.04 \mathrm{~m}$ & Number of nodes in y - direction & $\mathrm{Ny}=10, \Delta \mathrm{y}=0.3 \mathrm{~m}$ \\
\hline
\end{tabular}

Table 2: Temperature difference and noise of sol with solar irradiation (air velocity: $0.75 \mathrm{~ms}^{-1}$ ).

\begin{tabular}{lcl}
\hline $\begin{array}{l}\text { Solar irradiation } \\
\left(\mathrm{Wm}^{-2}\right)\end{array}$ & $\begin{array}{l}\text { Air Temperature Difference } \\
(\Delta \mathrm{T})^{\circ} \mathrm{C}\end{array}$ & $\begin{array}{l}\text { Noise of Sol } \\
\mathrm{oS}(\text { oncisol })\end{array}$ \\
\hline 450 & 15.50 & 28 \\
550 & 18.90 & 28.93 \\
650 & 22.40 & 29.7 \\
750 & 25.90 & 30.36 \\
850 & 29.40 & 30.91 \\
\hline
\end{tabular}

Table 3: Temperature difference and noise of scattering with air velocity $\left(S=650 \mathrm{Wm}^{-2}\right)$.

\begin{tabular}{llcl}
\hline Air velocity $\left(\mathrm{ms}^{-1}\right)$ & Fluid Power $\left(\mathrm{Wm}^{-2}\right)$ & $\begin{array}{l}\text { Air Temperature Difference } \\
(\Delta \mathrm{T}){ }^{\circ} \mathrm{C}\end{array}$ & $\begin{array}{l}\text { Noise of Scattering } \\
\text { oS (oncisip) }\end{array}$ \\
\hline 1.35 & 47.62 & 15.28 & 17.72 \\
1.05 & 37.0 & 18.22 & 16.50 \\
0.75 & 26.45 & 22.40 & 15.02 \\
0.45 & 15.87 & 28.15 & 12.65 \\
0.15 & 05.29 & 29.80 & 07.64 \\
\hline
\end{tabular}

Table 4: Mass flow rate and noise of therm with $(\Delta T)^{\circ} \mathrm{C}$.

\begin{tabular}{lllllllll}
\hline$(\Delta \mathrm{T}){ }^{\circ} \mathrm{C}$ & $\begin{array}{l}\text { Mass flow } \\
\text { rate } \\
\left(\mathrm{Kg} \mathrm{s}^{-1}\right)\end{array}$ & $\begin{array}{l}\text { Thermal } \\
\text { Power } \\
\left(\mathrm{Wm}^{-2}\right)\end{array}$ & $\begin{array}{l}\text { Noise } \\
\text { Therm } \\
\mathrm{OS} \text { (oncisol) }\end{array}$ & of & $\begin{array}{l}(\Delta \mathrm{T})^{\circ} \mathrm{C} \\
\text { Mass flow } \\
\text { rate }\left(\mathrm{Kg} \mathrm{s}^{-1}\right)\end{array}$ & $\begin{array}{l}\text { Thermal } \\
\text { Power } \\
\left(\mathrm{Wm}^{-2}\right)\end{array}$ & $\begin{array}{l}\text { Noise of therm } \\
\text { oS (oncisol) }\end{array}$ \\
\hline 15.50 & 0.01376 & 71.09 & 19.5602 & 15.28 & 0.0231 & 117.65 & 21.868 \\
18.90 & 0.01275 & 80.325 & 20.119 & 18.22 & 0.0171 & 103.85 & 21.296 \\
22.40 & 0.0120 & 89.6 & 20.614 & 22.40 & 0.0120 & 89.6 & 20.614 \\
25.90 & 0.0115 & 99.2833 & 21.043 & 28.15 & $8.1 \times 10^{-3}$ & 76.0 & 19.866 \\
29.40 & 0.0111 & 108.78 & 21.505 & 29.80 & $6.2 \times 10^{-3}$ & 61.59 & 18.898 \\
\hline
\end{tabular}

Table 5: Noise of elasticity with air particle velocity (Impedance $Z_{0}=413 \mathrm{~N} \cdot \mathrm{s} \cdot \mathrm{m}^{-3}$ at $20^{\circ} \mathrm{C}$ ).

\begin{tabular}{|c|c|c|c|c|c|c|}
\hline $\begin{array}{l}\text { Air } \\
\left(\mathrm{m} \cdot \mathrm{s}^{-1}\right)\end{array}$ & $\begin{array}{ll}\text { Fluid } & \text { Power } \\
\left(\mathrm{W} \cdot \mathrm{m}^{-2}\right) & \end{array}$ & $\begin{array}{l}\text { Noise } \\
\text { Scattering } \\
\text { oS (oncisip) }\end{array}$ & of & $\begin{array}{l}\text { Sound Pressure } \\
\left(\mathrm{N} \cdot \mathrm{m}^{-2}\right)\end{array}$ & $\begin{array}{l}\text { Sound Power } \\
\text { Intensity } \\
\left(\mathrm{W} \cdot \mathrm{m}^{-2}\right)\end{array}$ & $\begin{array}{l}\text { Noise } \\
\text { Elasticity } \\
\text { oB (oncibel) }\end{array}$ \\
\hline 1.35 & 47.62 & 17.72 & & 557.5 & 752.7 & 30.36 \\
\hline 1.05 & 37.0 & 16.50 & & 433.65 & 455.33 & 28.05 \\
\hline 0.75 & 26.45 & 15.02 & & 309.75 & 232.31 & 24.97 \\
\hline 0.45 & 15.87 & 12.65 & & 185.85 & 83.63 & 20.24 \\
\hline 0.15 & 05.29 & 07.64 & & 61.94 & 09.29 & 10.12 \\
\hline
\end{tabular}




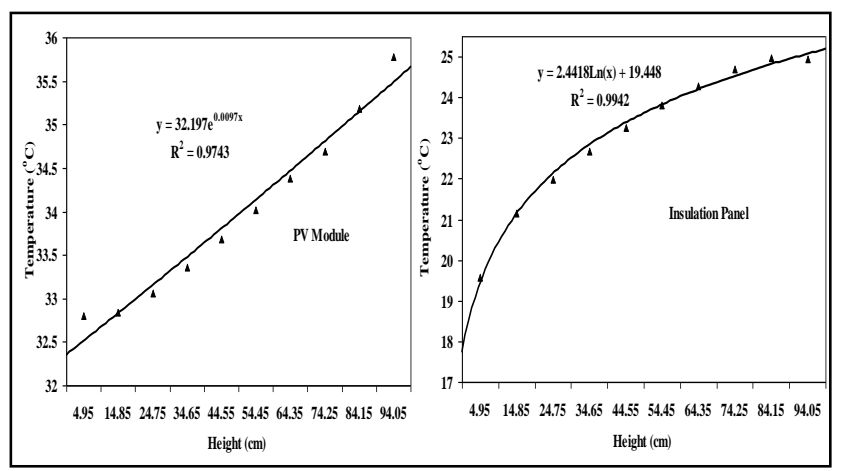

(a)

(b)

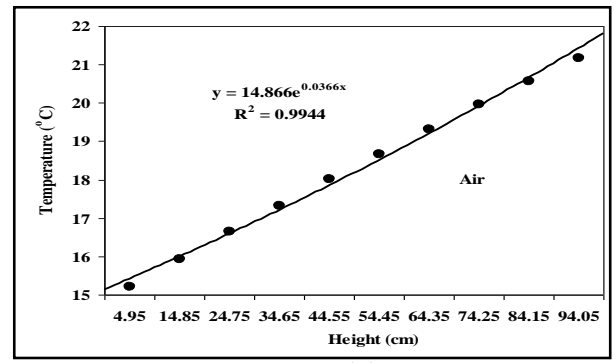

(c)

Figure 5: Thermal Model Results: (a) PV module; (b) insulation panel; and (c) air.

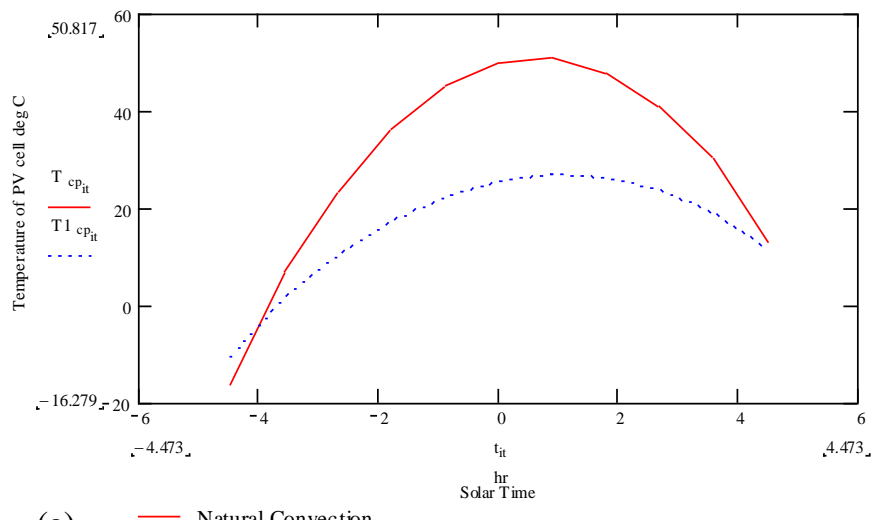

(a) $\quad \ldots$ Natural Convection

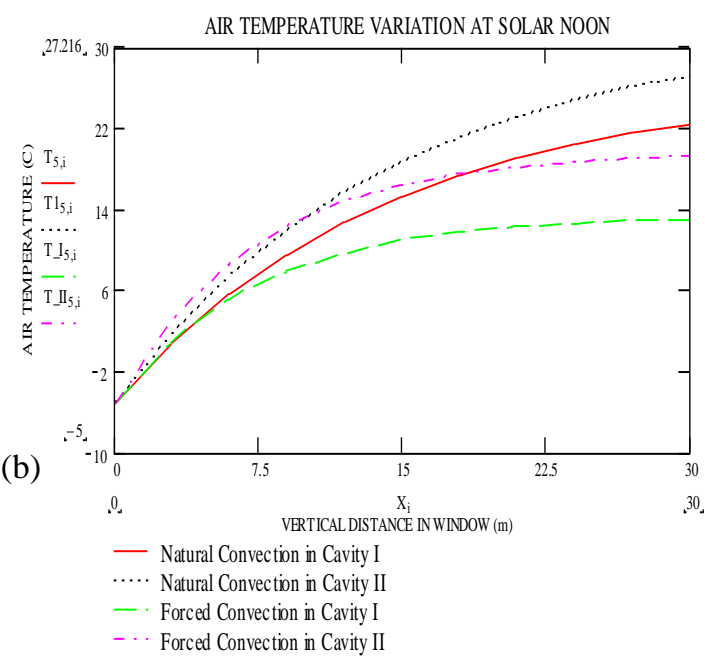

Figure 6: Thermal Model Results: (a) PV Module Temperatures; (b) Air Temperatures.

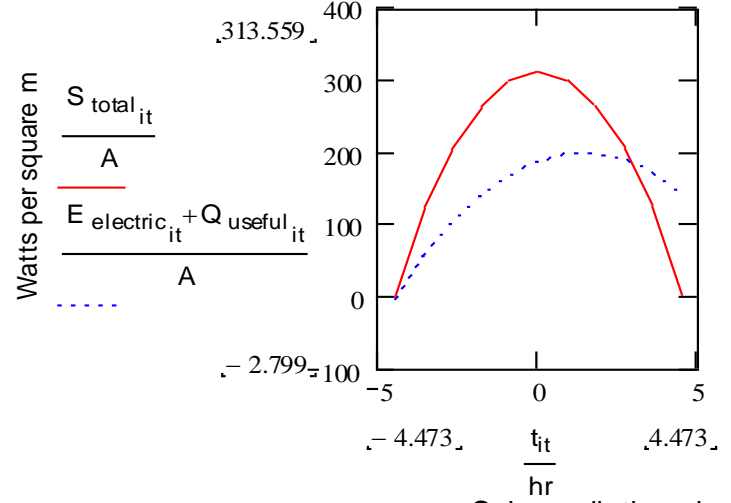

Solar radiation absorbed Useful Energy generated

Figure 7: Useful energy generated and solar energy absorbed by a photovoltaic module.

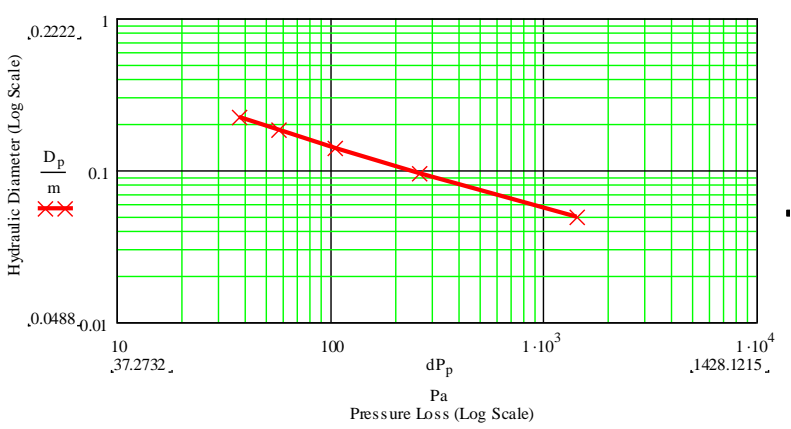

(a)

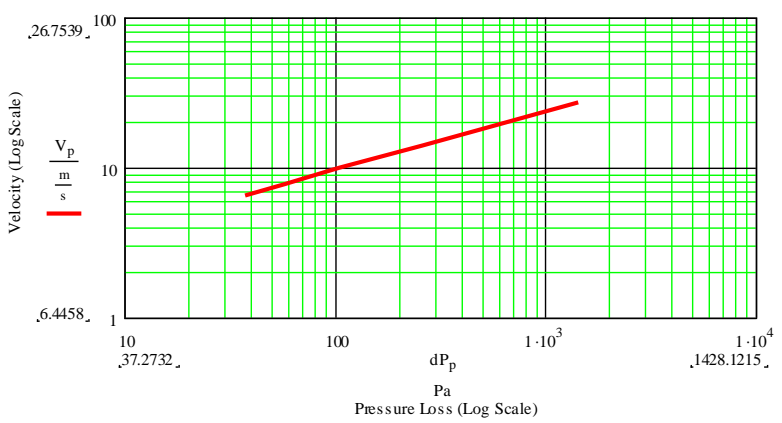

(b)

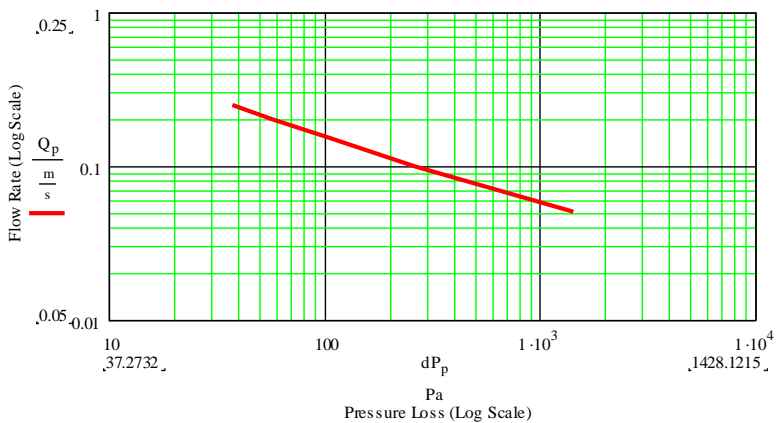

(c)

Figure 8: Variation of hydraulic diameter, velocity and flow rate vs pressure drop on a log scale.

\section{Conclusions}

A study on integrated insulation modeling of an airflow window with a PV solar wall via energy conversion is 
performed. The noise interference and characterization equations as per speed of a composite wave are presented. The sources of noise measurement equations (sun, light, sound, heat, electricity, fluid and fire) are described depending on their speed of noise interference. Noise measurement equations and their units are coined. The acoustic insulation systems are classified as per source signals of solar power, electric power, light power, sound power, heat power, fluid power and fire power.

Several performance and optimisation issues are considered in development of the model including optimal air velocity for heat transfer, dimensions of PV module (height), selection of cavity width to reduce pressure drops, and prediction of temperature rise of air as it flows out of the airflow window system and into the outdoor test-room. The airflow is adjusted to a constant value to optimise necessary temperature for integrated photovoltaic array as well as for pre-heated fresh air into the outdoor test-room. It is envisaged that inside an airflow window integrated with PV, cooling by forced convection is essential, without which, the temperature of PV cell reaches very high $\left(51^{\circ} \mathrm{C}\right)$, which decreases the efficiency by more than 20\% (Dehra, 2002). The combined efficiency (electrical and thermal) of the system reaches $50 \%$.

A Building Integrated Photovoltaic Airflow Window (BIPV-AW) system is developed for the purpose of combined generation of electricity, thermal energy and daylighting. This approach will have additional following advantages: a) there will be reduction in peak heating loads, which will reduce the required capacity of the heating/cooling system; b) there will be reduction in energy consumed for heating and lighting in the building; and c) electricity demand of the building will be reduced and energy utilities will get peak surplus.

\section{Acknowledgement}

The author conducted part of the work at Department of Building, Civil and Environmental Engineering, Concordia University, Montréal, Québec, Canada.

\section{References}

Asdrubali F., D'Alessandro F., Schiavoni S. (2015). A review of unconventional sustainable building insulation materials, Sustainable Materials and Technologies 4, pp. 1-17.

Asdrubali F., Schiavoni S. and Horoshenkov K. V. (2012). Review of Sustainable Materials for Acoustic Applications, Building Acoustics, Volume 19, Number 4, 2012, pp. 283-312.

Dehra, H. (2011). Modelling of an Airflow Window with a Photovoltaic Solar Wall, Proceedings from $10^{\text {th }}$ International Conference on Sustainable Energy Technologies (SET 2011), Istanbul, Turkey, 4-7 September, 2011, 6p.

Dehra, H (2007). A Unified Theory for Stresses and Oscillations, Proceedings from CAA Conf. Montréal.
2007, Canadian Acoustics. September 2007. Vol. 35. No. 3, pp 132-133.

Dehra, H. (2008a). Power Transfer and Inductance in a Star Connected 3-phase RC Circuit Amplifier, Proc. AIChE 2008 Spring Meeting, New Orleans, LA, USA, April 6-10, 2008, session 96a, 7p.

Dehra, H. (2016). A Novel Theory of Psychoacoustics on Noise Sources, Noise Measurements and Noise Filters, INCE Proc. NoiseCon16 Conf., Providence, Rhode Island, USA, 13-15 June, 2016, pp. 933-942.

Dehra, H. (2008b). The Noise Scales and their Units, Proc. CAA Conf., Vancouver 2008, Canada, Canadian Acoustics, Vol. 36 (3) 2008, pp 78-79.

Dehra, H. (2017). A Multi-Parametric PV Solar Wall Device, Proceedings from IEEE International Conference on Power, Control, Signals and Instrumentation Engineering (ICPCSI-2017), Chennai, India on Sep 21-22, 2017, pp. 392-401.

Dehra, H. (2018a). Modeling of Energy Conversion and Noise Characterization in Outdoor Ducts exposed to Solar Radiation, International Conference on Applied Energy (ICAE 2018), Hong Kong, China on Aug 2225, 2018. Energy Procedia, Feb 2019, pp. 5162-5168.

Dehra, H. (2018b). A Paradigm of Noise Interference in a Wave, Internoise-2018, $47^{\text {th }}$ International Congress and Exposition on Noise Control Engineering, Chicago, Illinois, USA on Aug 26-29, pp. 451-462.

Dehra, H. (2018c), Acoustic Signal Processing and Noise Characterization Theory via Energy Conversion in a PV Solar Wall Device with Ventilation through a Room, Advances in Science, Technology and Engineering Systems Journal, Vol. 3, No. 4, 2018, pp. 130-172.

Dehra, H. (2018d). Characterization of Noise in Power Systems, Proceedings from IEEE International Conference on Power Energy, Environment \& Intelligent Control (PEEIC2018), Greater Noida, India on April 13-14, 2018, pp. 320-329.

Dehra H. (2004). A Numerical and Experimental Study for Generation of Electric and Thermal Power with Photovoltaic Modules Embedded in Building Façade, Submitted/Unpublished PhD Dissertation, Department of Building, Civil and Environmental Engineering, Concordia University, Montréal, Québec, Canada, 30 August, 2004 (120 pp.).

Dehra, H (2002). Modelling of airflow window with integrated photovoltaics, Doctoral Seminar, Department of Building, Civil and Environmental Engineering, Concordia University, Montréal, Canada, April 2002.

Dehra, H. (2019). Principles of Energy Conversion and Noise Characterization in Air Ventilation Ducts exposed to Solar Radiation, Applied Energy, 242C (15 May 2019), pp. 1320-1345. 